\title{
TERRITORIAL BEHAVIOR IN MALES OF PHILANTHUS PSYCHE (HYMENOPTERA, SPHECIDAE)*
}

\author{
By KeVIN M. O’NeILL \\ Department of Zoology and Entomology \\ Colorado State University \\ Fort Collins, Colorado 80523
}

\section{INTRODUCTION}

The comparative ethology of the family Sphecidae has been the subject of intensive study over the last thirty years, although the behavior of these wasps was observed and recorded by Fabre as early as the mid-1800's. The majority of work has been done on females, probably because of the conspicuousness of their activities and their complex, species-specific behavior patterns. In the past few years, an increasing amount of work has concentrated on the behavior of male sphecids, revealing complex and sometimes puzzling behavior patterns. Lin's paper (1963) on male territoriality in Sphecius speciosus was one of the first attempts at a rigorous study of male behavior. The conspicuousness of female activity is often matched by the inconspicuousness of the males, particularly when they do not frequent the nesting area subsequent to emergence. Even when males are easily observed, in the nesting area or elsewhere, matings are rarely observed. Male sphecids, except in a few species, do not participate in the nesting activities of the females.

Alcock et al. (1978) classify the mating strategies of male aculeate Hymenoptera as taking the form of either searching for females (e.g., the "sun dance" of Nyssonine sand wasps, Evans 1966) or waiting for (e.g., territoriality) females at particular localities where they are most likely to be found. The distribution of receptive females in time and space has been a major influence on the evolution of male mating strategies. A recent review of territorial behavior in male sphecids (Alcock 1975a) shows that in all known cases this behavior is associated with securing females for copulation. I define territoriality here as "a fixed area from which intruders are excluded by some combination of advertisement, threat or

*Manuscript received by the editor March 27, 1979. 
attack" (Brown 1975). Since territoriality is the exception rather than the rule in male sphecids, some ecological factors must impinge, favoring the evolution of the behavior in some species and not in others. According to Alcock, territoriality seems to evolve when males can locate areas where females are clumped or occur predictably. In addition, these areas must be defendable in terms of the time and energy budgets of the males. Lacking these conditions the large time and energy expense associated with defending a territory may not maximize reproductive success.

Recently particular attention has been paid to male and female behavior in the sphecid genus Philanthus. In most North American species in which male behavior has been observed males exhibit territoriality. They also exhibit a specific behavior referred to as abdomen dragging which has been suggested to function in scent marking the territories with a mandibular gland secretion (Gwynne 1978) which may attract females (Alcock 1975a).

Philanthus psyche Dunning is a relatively small member of its genus, females and males averaging 9 and $8 \mathrm{~mm}$ in length, respectively. It is found in western and central North America (Great Plains and Great Basin) occupying sand dunes with low sparse vegetation, particularly grasses. Nesting areas are usually on the periphery of blowouts or similar dunal features.

\section{MeTHODS}

Observations on Philanthus psyche were made about two miles east of Roggen, Weld Co., Colorado during July and August 1976 and 1977 and occasionally throughout the summer of 1978. The general study area may be classified as sand sagebrush (Harrington 1964). The specific study site was the area immediately surrounding a vegetation-free blowout, one side of which was bordered by a sandy ridge. The nesting area of $P$. psyche was in the border of the blowout and was level to slightly sloping. It was dominated by blowout grass [Redfieldia flexuosa (Thurb.) Vasey] and lanceleaf scurfpea (Psoralea lanceolata Pursh). Further away the dominant plants were sunflower (Helianthus spp.) along with various grasses.

At the main observation area measuring 12 by 8 meters, detailed observations were made of male and female behavior and of locations of marked males, occupied territories and female nests. Individual males were marked with one or two spots of enamel paint 
on the thorax. Periodic observations were made of other areas where there were territorial males to compare male behavior and territory and nest distribution, and to check for movement of marked males between the areas.

Wind speed measurements were made with a Datametrics Airflow multimeter Model 800 VTP anemometer. Males and females for dissection were preserved in alcoholic Bouin's solution which maintains the turgidity of the glandular tissue (Humason 1967).

\section{RESULTS}

\section{Daily Activity Patterns}

At Roggen, males and females emerge in late June, the males preceding the females by a few days to a week. Both become active daily at about 1000 and remain so until between 1400 and 1600 hours. Females spend the night in the nest while males sleep in short $(6 \mathrm{~cm})$ sleeping burrows which they dig. After emergence from these burrows each morning, males perch on the low vegetation in the nesting area, grooming and occasionally changing perches but not interacting with other insects, even digging females. Males begin setting up territories, on warm clear days, between 1030 and 1100 .

For seven different clear days during the summer of 1977 , twelve territories in the main observation area were censused every 15 minutes during the observation period. Only $22 \%$ of the territories observed at 1100 were occupied. However, from 1130 until 1300 approximately $50 \%$ were occupied on the average. The number thereafter declined, few males being present by 1600 . On warm clear days at the peak of seasonal activity, nearly $100 \%$ of the territories were occupied during the afternoon hours; on overcast days, few males were territorial.

\section{Location and Characteristics of Territories}

Both nests and territories occurred in areas of generally short, sparse vegetation rather than in nearby areas of relatively high and dense vegetation or open sand (Figure 1). The mean distance from a nest to the center of the nearest territory was only $35 \mathrm{~cm}(\mathrm{~N}=29$; S.D. 17.4; see Figure 2). Where both P. psyche and P. albopilosus occur in the same habitat, the former nests in the peripheral areas around the blowout which contain plants, while the latter nests in the bare, fine-grained sand in the central portion of the dune. This is the situation at Roggen (Evans 1975). The open sand poses restric- 


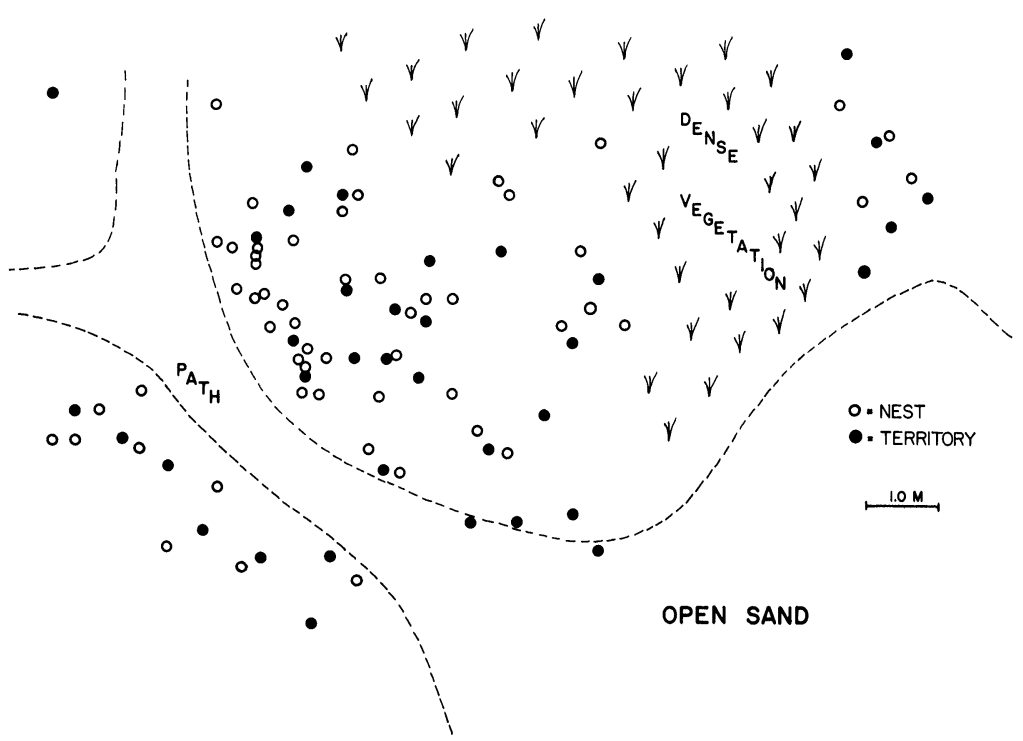

Figure 1. Map of main observation area showing vegetation, nests and territories.

tions to nesting. For species such as $P$. albopilosus which nest in the open sand, it may be adaptive to dig much deeper nests because shifting sands can disrupt the cells in the nest. Mean cell depth for $P$. psyche and $P$. albopilosus at Roggen are 21.5 and $52.0 \mathrm{~cm}$, respectively (Evans 1975 and unpublished data). The ability of females of $P$. psyche to nest in the peripheral area with stabilizing vegetation allows them to dig shallower nests and possibly more per season and to avoid the high surface temperatures of the open sand during the middle of the day.

On the other hand, areas of more dense vegetation may restrict nesting due to the fact that plant roots interfere with digging. Therefore, although plants stabilize the dune, females require at least a small amount of space between plants for digging. Nests occurred in small bare spots in the vegetation at least a short distance from the base of the plants. Female $P$. psyche consistently nest in this type of situation, not only in the Roggen area (where the species is extremely abundant), but also in other areas of Colorado and New Mexico where I have observed this species.

It was evident that males set up territories in small plots devoid of vegetation (or nearly so) within the nesting area (Figure 2). By 
recording the location of plants on which males "scent marked" around the territory and perching points on the sand and marking off the area which they encompassed, a rough measure of territory size can be made. These areas visibly coincide with the bare areas of sand occupied by males in the field. (If we chose, instead, to take the boundary of the territory as the maximum distance from its center at which a male will sight and approach a passing insect, the above measurement would be only a slight underestimate of functional territory size.) The mean size for twelve territories was $0.17 \mathrm{~m}^{2}$

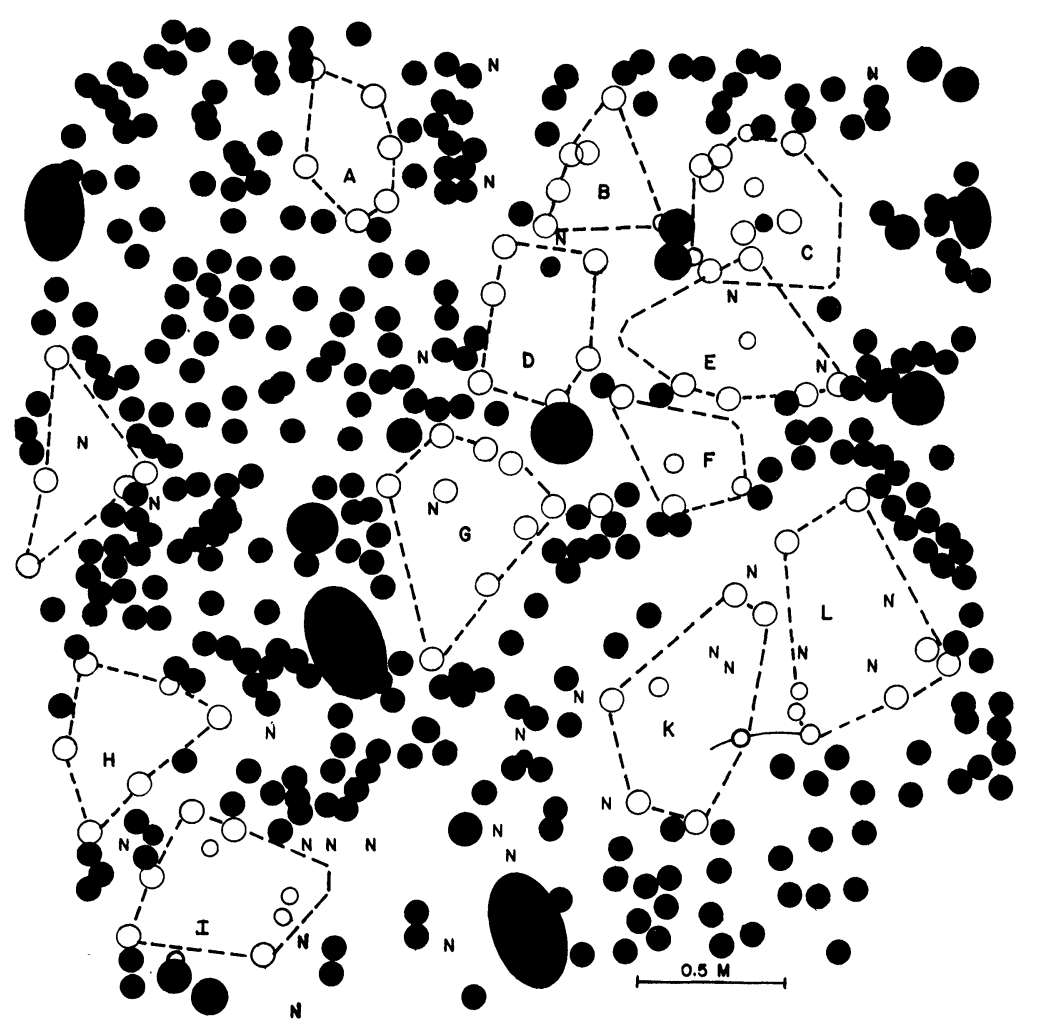

Figure 2. Map of $3 \mathrm{~m}^{2}$ area in which most observations were made in 1977. Dotted lines indicate the area encompassed by all marked plants and/or perches of male(s). For several territories it was necessary to record, on two separate days, plants marked by different males. Solid circles and ovals indicate plants that were marked by males. $\mathrm{N}$ indicates a nest entrance. 
(range 0.10 to $0.25 \mathrm{~m}^{2}$ ). It was not apparent that territory size changed through the season as has been shown for the territorial bee Hoplitus anthocopoides (Eickwort 1977).

\section{Patterns of Territory Occupation}

Both casual observation and censusing showed that certain territories were occupied more frequently than others. Three of the twelve territories censused (A, K and D in Figure 2) were occupied at least $85 \%$ of the time in which at least one of the territories in the plot contained a territorial male. Territory $\mathrm{D}$ was occupied during $95 \%$ of the period. These territories and several others were usually occupied during peak activity periods. Others contained males only sporadically, often for a few consecutive days followed by a lull of a week or more. Furthermore on overcast days and during the latter part of the season, when few males were territorial, males were nearly always observed on the most "popular" territories. In contrast to these, five territories censused (B, E, F, G and $\mathrm{H}$ ) were each occupied less than $30 \%$ of the time.

For eleven of these territories, there was information on both size and frequency of occupation. Comparison of these two parameters shows no appreciable relationship between size and quality of the territory, the latter determined by the frequency of occupation $(r=$ 0.316; regression not significant). Therefore, the size of the territory (through the given range) or at least of the vegetation-free perch area does not seem to be a factor in choosing a territory, although there is probably a minimum acceptable space that males will utilize.

For certain males that were watched continuously or were marked with paint, it was possible to record approximately how long they occupied a certain territory on a given day. The mean duration of occupation of a territory was 80 minutes $(\mathrm{N}=25$; S.D. $=45$ minutes).

During the summer of 1976 , the distribution of territories occupied by individual males was recorded within observational limits. Probably due to the difficulty of marking these small wasps without killing them or hindering their movement, only 13 males were seen subsequent to the day on which they were marked, with only six being observed two or more times. The maximum time period over which a marked male was seen was fourteen days and the maximum 
number of territories a marked male was seen to occupy was nine. Fifty-two territories were recorded for males returning after the day on which they were marked. Of these, forty-six $(88 \%)$ were in the area of grass in which they were originally marked (area in Figure 1). Only six (12\%) were recorded outside this area with only one being more than $5 \mathrm{~m}$ away. These six were found during periodic checks of nearby areas (within $50 \mathrm{~m}$ ) where there were known to be territories and it is possible that others were missed because of the area to be covered.

Intraspecific and Interspecific Interactions

Much of the male's time while on the perch is occupied by interaction with intruding insects, particularly conspecifics. An intruder is defined as an insect that flies into or through a territory (or immediately adjacent to it). A male's response towards an intruder may fall into one of two functional categories: aggression towards a conspecific male or investigation of a potential mate. Barash (1977) designates aggression as an interaction between individuals with the result that one must relinquish access to some resource important to its fitness. It is difficult in this species to distinguish between these two functional responses. However, observations support the fact that at least one type of male-male interaction (the swirling flight) represents aggression, suggesting that $P$. psyche exhibits true territorial behavior. The swirling flight consists of two (or rarely three) males repeatedly circling one another in loops with a radius of 5 to $15 \mathrm{~cm}$, at a speed making them difficult to follow. These flights usually last from less than 1 to approximately 10 seconds. The term was used by Alcock (1975a) to refer to a similar behavior in males of $P$. multimaculatus. Swirling flights take place between males holding adjacent territories or between territorial and non-territorial males, the latter probably trying to usurp the former's area. Since they take place repeatedly between the same two males over a short period of time, it is unlikely that this behavior could be continued mutual investigation of a potential mate. Swirling flights do not resemble any observed male-female interaction, and are usually terminated by the intruder leaving the immediate area. However, on three occasions at least, it was observed that the continual harassment by the intruder resulted in its usurping possession of the resident's territory. I assume that 
this may have been a relatively common occurrence, since territories often changed hands (noticed during periodic scans of the territories). Non-contact aggressive behavior is known for the males of several other species of insects: conocephaline grasshoppers (Morris 1971), praying mantids (Edmunds 1967), cockroaches (Breed 1972), the sphecid Eucerceris flavocinctus (Steiner 1978) and nymphalid butterflies (Baker 1972). Baker reported that intruding males in the species Inachis io may usurp another male's territory without physical contact, using a behavior similar to the swirling flight.

One other type of interaction seems to be a form of aggression at first glance. A territorial male will drop from a height of approximately 10 to $30 \mathrm{~cm}$ onto the back of a male perched on the ground. The perched individual may be within the male's territory or an adjacent territory and does not necessarily have to move to elicit the "attack." The striking male seemingly discontinues the encounter himself immediately leaving after a grapple of one second or less. Alcock (1975a) refers to this as "strike and flee" in P. multimaculatus. A similar behavior was observed when a male hovered above and dropped onto the back of a female working at her nest entrance or one that had landed within his territory. As with male-male grapples, the striking male orients head-to-head with the female when landing upon her. This is the posture necessary to initiate copulation. For these interactions the period of grappling was longer (several seconds) and was terminated when the female managed to break free of the male's grasp. Occasionally two males were seen simultaneously grappling a female in this manner. Upon breaking free, the female continued working on the nest or flew away a short distance, perching on the sand for a short period of time before returning. The latter behavior is similar to parasite avoidance noted for this and other species of Philanthus (Evans 1970) and may function to reduce the number of energetically expensive encounters with males. The encounter may be repeated and may result in the female losing her prey. The similarity of this behavior ("strike and flee") towards both males and females suggests that the motivation behind it is the same. In other words, the male is pouncing upon a potential mate and terminates the interaction himself when some proximate cue signals that it is not a conspecific female. This has been suggested as an explanation for a similar form of male-male interaction in the western cicada-killer wasp, Sphecius grandis (Alcock 1975b). Therefore, the swirling 
Mean distance intruder pursued by males $(\mathrm{cm})$

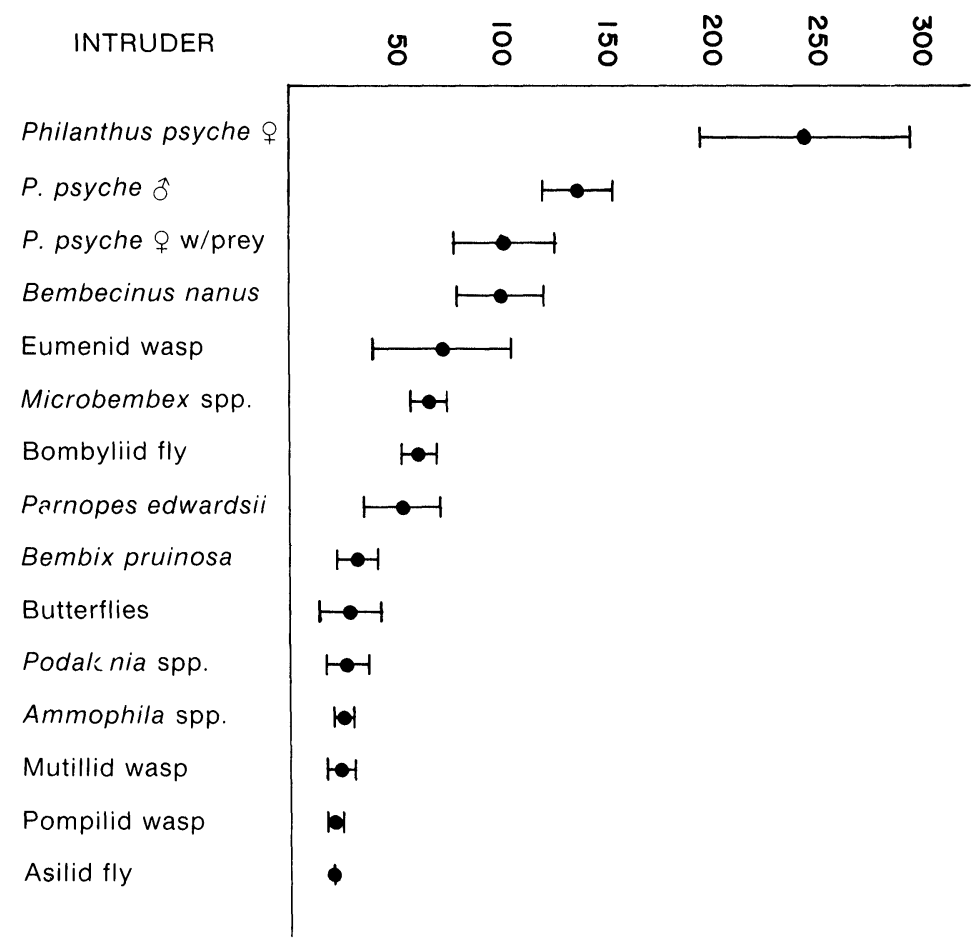

Figure 3. Intensity of response (distance pursued) of male P. psyche for each species of intruder. Intruder species are on the horizontal axis, arranged from left to right in order of decreasing similarity to a conspecific female (see Table 1).

flight seems to be the only distinctive aggressive male-male interaction in $P$. psyche.

A frequent response of a male to an intruder involved approach and/or pursuit of an insect passing through or near the territory. Different insects were pursued different distances by the territorial males, some simply being approached with the male not leaving his territory. Others were pursued relatively long distances. The question arose that if there is a relationship between the distance pursued and the identity of the intruder, is the intensity of the male's response (distance pursued) based upon the similarity of the intruder to male or to female conspecifics (i.e., is the response aggressive or an attempt at securing a mate, respectively)? In order 
to answer this, I measured the distance pursued by a male when possible to identify the intruder. Distance pursued refers only to those encounters in which males chased an insect that flew straight through or adjacent to the territory. It does not include swirling flights in which the intruder's response would complicate measurement of the resident's response. If the response was a simple instantaneous approach, the encounter was given an a priori value of $20 \mathrm{~cm}$ since this approximates the radius of the territories. The male did not make contact with the intruder in mid-air as occurs in other territorial sphecids (Lin 1963, Alcock 1975a, Gwynne 1978) except in a few cases where conspecific females were grappled at the end of a flight. For two hundred forty-seven responses to intruders of thirteen different species (minimum of seven per species), I was able to record the pursuit distance. Many more encounters were observed, but could not be recorded either because the distance or the identity of the intruder could not be accurately determined. The responses to conspecifics were differentiated into female, male, and female with prey. Gwynne (1978) has carried out a similar analysis with $P$. bicinctus using distinct levels of behavior (approach, butt, grapple and grapple to ground, in increasing order) as a measure of response intensity. The intruder species can be used as "natural models" of female conspecifics and one may compare the intensity of response to the degree of similarity to the female. Figure 3 shows the mean distance pursued for each type of intruder. If we compare these distances to a list of characteristics of each type of intruder (Table 1) we see that the degree of similarity to the female is roughly positively correlated with the intensity of response of the male. There is at least a rough relationship with response intensity (distance) for all characteristics considered, so it is difficult to determine to which the male responds and which are most important.

As with $P$. bicinctus the response is greatest towards the females not carrying prey. The response to females ranged from 1.4 to $4.0 \mathrm{~m}$ $(\mathrm{N}=13$; mean $=2.45 \mathrm{~m})$. Several times it terminated with the male pouncing upon the female. The response to males averaged much less $(\mathrm{N}=13$; mean $=1.37 \mathrm{~m}$; range 1.0 to $2.0 \mathrm{~m}$; t-test for difference between females and males significant, $\mathrm{p} \leq .0001$ ) but the attribute responsible for this difference was not distinctly discernable. Apparently some subtle difference between male and female flight characteristics is sufficient to elicit responses of different intensities 
by the territorial males. It is evident that the pursuit response as measured above was investigative rather than aggressive. The response becomes aggressive only if a pursued male reacts and a swirling flight ensues.

The response to females with prey is less than that to males ( $p \leq 0.016$; t-test) and females without prey. The proximate cause for this may be that the female with prey flies slower and is bulkier in appearance because of the burden she carries. An ultimate cause may be that the females with prey are not sexually receptive, having in all likelihood mated prior to or early in the sequence of nest provisioning.

Species that differ greatly in appearance and habits from female $P$. psyche, such as male velvet ants, spider wasps, asilid flies, butterflies and Ammophila spp. were merely approached or chased a short distance (never more than $70 \mathrm{~cm} ; \mathrm{N}=110$ ). In contrast, Bembecinus nanus, a sphecid wasp similar in appearance and habits to conspecific females, drew nearly the same response as females with prey (t-test, difference not significant). Coloration seems to be an important characteristic, but not the only one to which the males cue. This is evident because the bombyliid fly and the cuckoo wasp, which differ greatly in appearance from the females, usually (twentyeight of thirty-four cases combined) drew more than a simple approach response from the males. The response to these two was significantly different $(\mathrm{p} \leq 0.05)$ than that given to Bembix pruinosa (=B. pallidipicta) a sphecid with color patterns similar to $P$. psyche but of differing flight characteristics. Evidently, flight characteristics (speed and/or flight pattern) of the intruder are involved in motivating the male.

\section{Predation Upon Males}

One possible constraint upon the evolution of a mating system is the susceptibility to predation which a particular strategy imposes upon the males. There is a perceivable risk of predation by visually hunting robberflies (Asilidae) caused by the exposure of males during the large number of flights they take while on the territories. The risk is particularly high when these flights are directed towards robberflies intruding on the territory. Robberflies constituted almost $5 \%$ of the intruders that the males approached and/or pursued while territorial. Four attempted predations were observed, two of these successful. Predation will be discussed in more detail in another paper (Gwynne and O'Neill in press). 


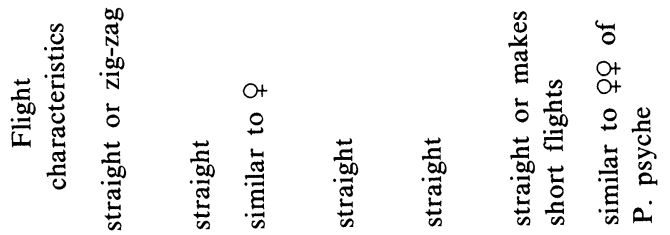

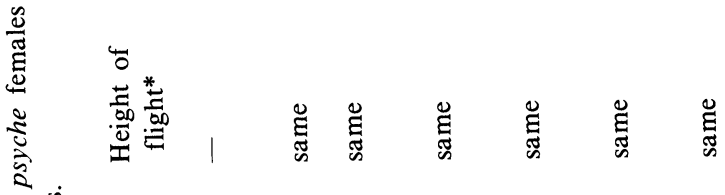
ज.

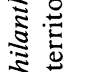

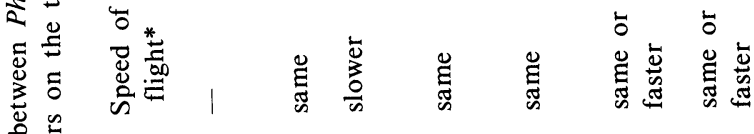

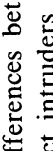

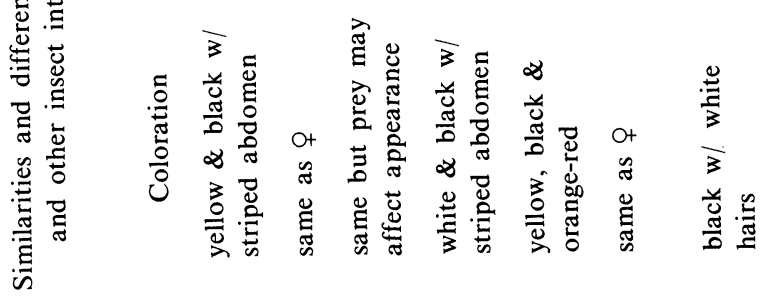

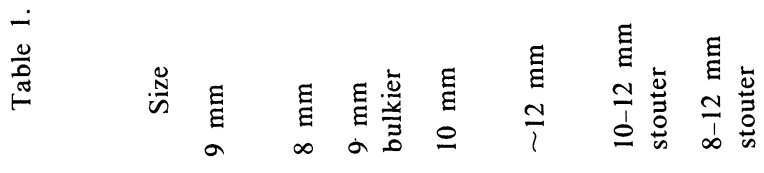

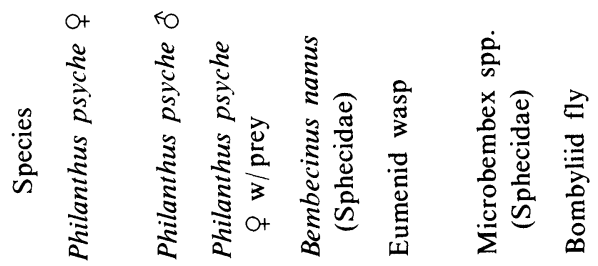




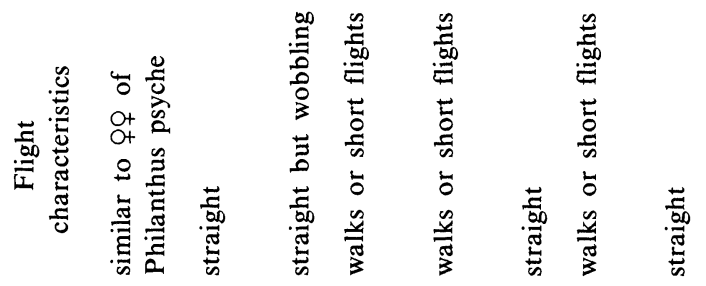

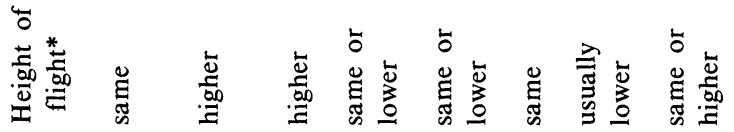

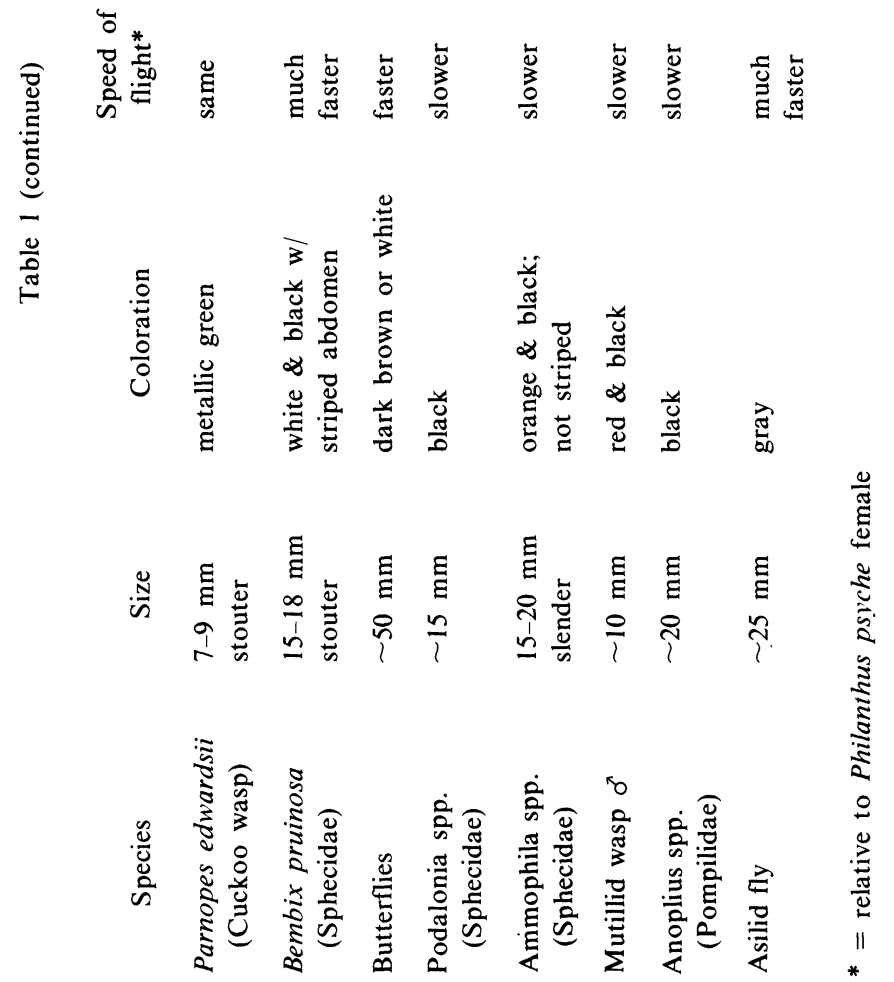


Abdomen Dragging and Scent Marking

A common behavior of males on territories is abdomen dragging. All species of Philanthus known to be territorial exhibit this behavior. Abdomen dragging begins by the male flying from his perch on the sand to a plant in or bordering his territory (usually blowout grass or lanceleaf scurfpea). Upon landing, the male walks along the stem or leaf in an inverted $\mathrm{V}$ position, the mandibular area and the posterior venter of the abdomen touching the plant. The abdomen is also "waggled" back and forth while in contact with the stem. The average number of times a male dragged his abdomen in a 5 minute period was $7.75(\mathrm{~N}=20$; S.D. $=3.8)$. Alcock $(1975 \mathrm{a})$ has suggested that a pheromone is being deposited by the male during abdomen dragging functioning to attract conspecific females to the territory for the purpose of mating. Although no bioassays were conducted, several lines of evidence suggest that this may be the case.

In nearly all cases (e.g., twenty-three of twenty-five for one male) abdomen dragging is preceded by what I will term a weaving flight. The male leaves his perch and flies back and forth about $10 \mathrm{~cm}$ above the ground, always perpendicular to wind direction and facing into it. The lateral portion of the flight is wide (up to about 30 $\mathrm{cm}$ ) at first, but usually narrows down to the vicinity of one upwind plant (Figure 4). I have also observed a similar flight in P. pulcher and $P$. tarsatus (unpublished). $P$. multimaculatus also makes short flights downwind of and facing the plant on which it perches and drags its abdomen (Alcock 1975a). If a chemical is being deposited, economical use of the male's pheromone supply could involve some way in which he could receive feedback on the airborne concentration in order to regulate the rate of scent marking. The weaving flight places the male in a position to detect the pheromone since he is downwind of the source. Interestingly enough, although a weaving flight usually precedes abdomen dragging, it often ends with the immediate return of the male to his perch. At some point during the weaving flight the male (after testing the airborne pheromone concentration) may make the decision whether to scent mark or not.

Wind direction affects the behavior of males associated with abdomen dragging and the weaving flight. For five males observed only seven of two hundred and six (3.4\%) abdomen draggings were on plants downwind of the perch, while one hundred eighty-two $(88.3 \%)$ and seventeen $(8.3 \%)$ were on plants upwind of and lateral 

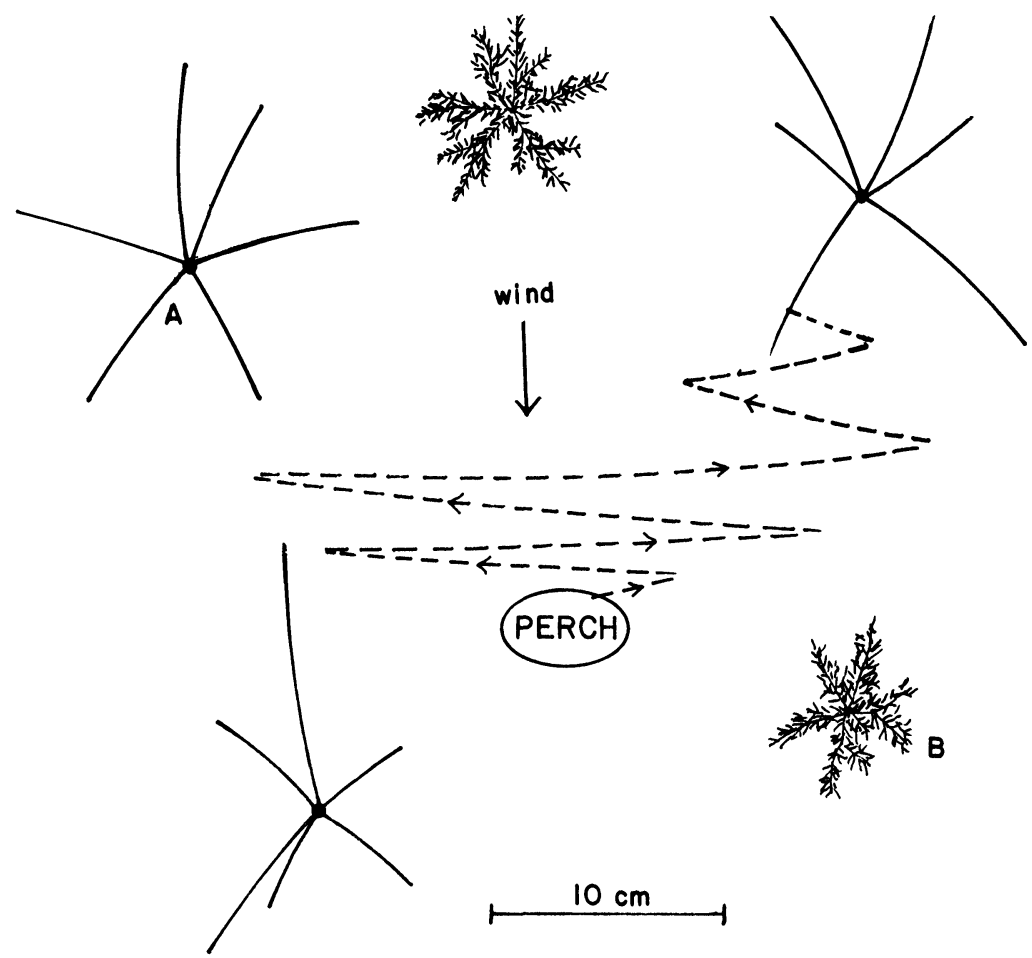

Figure 4. The weaving flight of the male. The solid arrow indicates the wind direction. The dashed line indicates the flight path of the male.

to the perch, respectively. Even when plants downwind of the perch were marked, the male often flew downwind of the plants before dragging his abdomen.

When wind direction reverses, perches moved to the opposite side of the territory and different plants were marked (Figure 5). In another area when vegetation was more sparse, males often had only one plant per territory and would always perch on the downwind side. The relative position of the perch to the plants on which the male drags his abdomen, as determined by wind direction, may be related to the same reason that the weaving flight occurs (i.e., he is in a position to detect the pheromone). Since he faces or is lateral to over $95 \%$ of the plants which he has marked the male is also in position to detect any females which have landed upon or near them. 
Wind velocity also affects abdomen dragging behavior. The mean wind velocity (measured every 15 seconds) and the wind velocity when the males initiate abdomen dragging were recorded for six different males (20 minutes of observation each; two 5 minute periods for determining mean wind velocity were alternated with two for measuring velocity at the initiation of abdomen dragging). For the total 120 minutes, the mean wind velocity was 34.3 $\mathrm{m} /$ minute $(\mathrm{S}: \mathrm{D} .=32.5)$ while the mean wind velocity at the initiation of abdomen dragging was $60.1 \mathrm{~m} /$ minute $(\mathrm{N}=87$; S.D. $=$ 27.5) (Figure 6). The means were significantly different (t-test, $\mathrm{p} \leq$ 0.001 ). Using readings taken to find mean wind velocity as the expected values the distributions were shown to be significantly

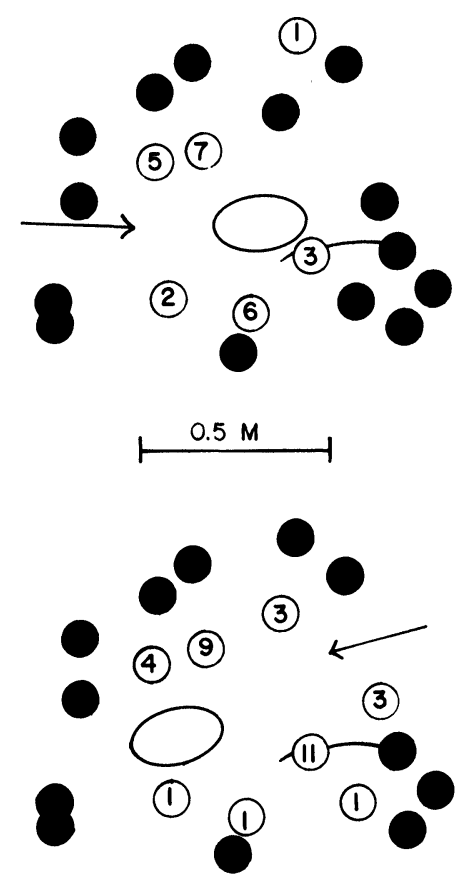

Figure 5. The effect of wind direction on position of the scent-marked plants for territory $\mathrm{K}$ (see Figure 2). Solid arrow indicates wind direction which on different days may come from different directions. Solid circles are plants not scent marked. Hollow circles are marked plants with the number of times it was marked in 10 (above) and 15 (below) minutes. The ellipse is where the male perched on the sand. 


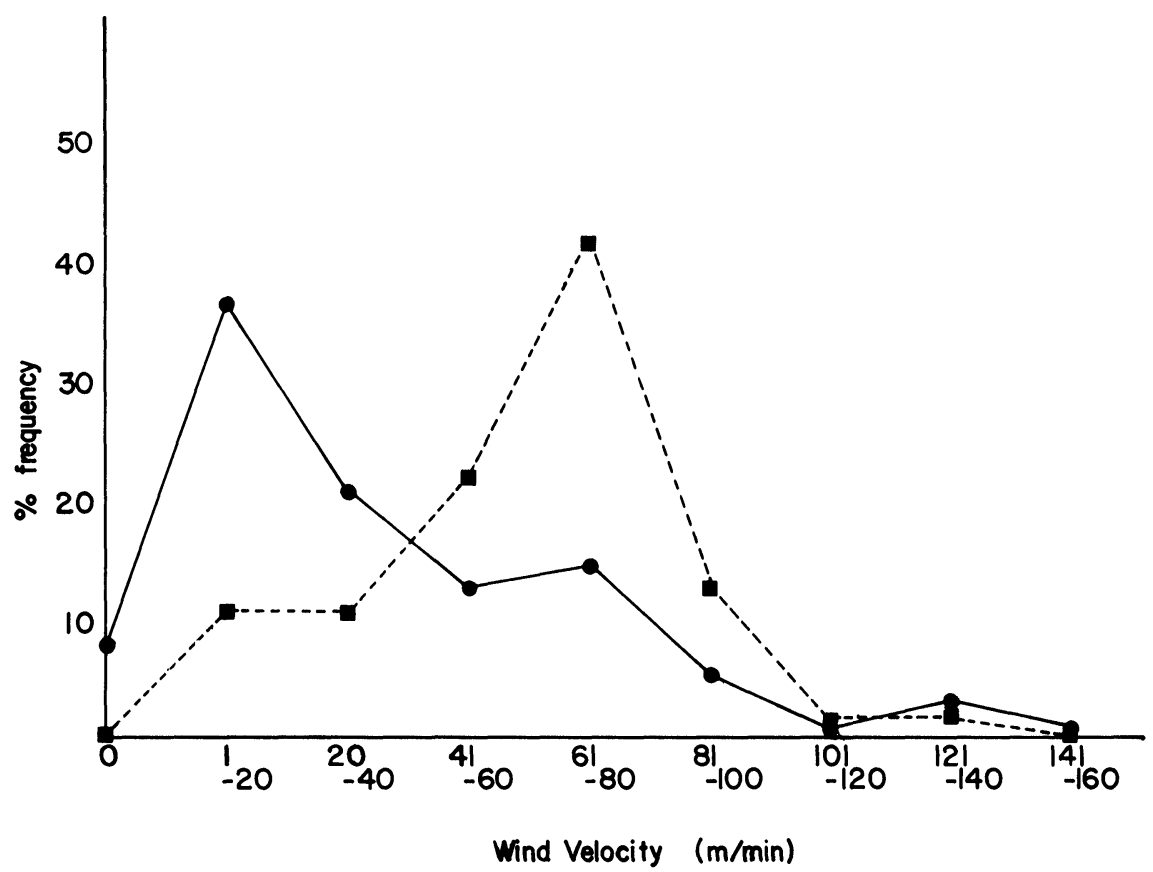

Figure 6. Frequency distribution of wind velocity readings, grouped in 20 $\mathrm{m} / \mathrm{min}$. intervals. The solid line indicates distribution of readings taken to measure mean wind velocity $(\mathrm{N}=287)$. The dashed line indicates frequency distribution of readings taken at initiation of abdomen dragging.

different $\left(\chi^{2}=89.8 ; 8\right.$ d.f.; $\left.\mathrm{p} \leq 0.001\right)$. Thus, there may be an optimal wind velocity range above and below which the males scent mark less often. Indeed, for the above males, $76 \%$ of all abdomen draggings were done at wind velocities between 41 and $100 \mathrm{~m} / \mathrm{min}$ ute, while only $31.8 \%$ of the overall wind velocity readings were in this range $(\mathrm{N}=287)$. A general conclusion might be made that males do not scent mark randomly with respect to the wind, but in some manner (possibly during the weaving flight) cue to the wind velocity and adjust their marking behavior accordingly. In fact, detection of wind velocity during weaving flight may be its function alternative or simultaneous to monitoring airborne pheromone concentration. Sower et al. (1973) have shown that for a species which releases a sex pheromone in discrete pulses, there are both upper and lower limits to wind velocity between which communication is feasible. 
This may be the situation in $P$. psyche and other species in the genus which scent mark. Even in a short-range communication system, conservation of energetically costly pheromone supplies should involve consideration of wind speed.

There is a line of morphological evidence supporting the idea that abdomen dragging serves to scent mark. Two parts of the male's body (excluding the legs) are in contact with the plant while abdomen dragging occurs, the mandibular area and the distal venter of the abdomen. A small tuft of hair, termed the clypeal brush (Bohart and Grissell 1975), is located near the base of the mandibles at the point where the head touches the plant. It is possible that the pheromone could be applied to the plant via the clypeal brush, the chemical itself being produced in the mandibular glands (Gwynne 1978). Close examination of the brush (prior to preservation in Bouin's solution) reveals that the hairs adhere to one another as if saturated with a liquid. Hair tufts are known to be associated with the deposition of trail pheromones in ants (Fletcher and Brand 1968).

Dissection of the male heads reveals a large pair of mandibular glands which nearly fill the portion of the head cavity beneath the eyes. This is also true for P. bicinctus (Gwynne 1978) and other species of Philanthus which I have examined (gibbosus, tarsatus, zebratus, crabroniformis and pacificus). The last two also have clypeal brushes but are not known to set up territories or to exhibit abdomen dragging, so it is possible that the glands serve some other function. $P$. albopilosus is the only species that $\mathrm{I}$ have examined in which the males have neither clypeal brushes nor large mandibular glands. This species does not exhibit abdomen dragging or establish territories (Evans 1975). The presence of clypeal brushes in most Philanthus, as well as in other genera of the subfamily Philanthinae, suggests that the absence of the brush in this species is a derived character. The mandibular gland as a source of pheromones is well documented in the Hymenoptera (Wilson 1971).

The third structure associated with the deposition of a pheromone is a brush of hair on the venter of the abdomen which is more diffuse than the clypeal brush but covers a wider area. There are no known glands associated with the hair brush (Evans personal communication). This hair brush may serve to spread the pheromone more evenly on the stem, facilitating evaporation. The abdominal and clypeal hair brushes are not present in females of this species. While 
perched on the territory the males spend time grooming, particular attention paid to the mandibular area and the venter of the abdomen.

\section{Mating}

Three matings were seen in the nesting area and none elsewhere. Two of these were observed already in progress, the male and female coupled on a stem in the territorial area. The third copulation was initiated when a female flew upwind (orienting to pheromone?) and landed on the edge of a territory. The resident male immediately pounced upon her. They coupled at once and flew to a plant about 1 $\mathrm{m}$ away where they remained still for about 4 minutes. At this point and again several minutes later, a second male landed on the back of the female resulting in the original pair changing perches once. They finally uncoupled after 8 minutes and 30 seconds. It was common to see females flying upwind through the territorial area in a low zigzag flight.

\section{DISCUSSION}

The mating strategy that males of a particular species adopt during the course of evolution can be evaluated in terms of probabilities. The optimal strategy is one which most often places the male in the right place at the right time to intercept or attract a sexually receptive female. The nature of this strategy is influenced by the habits of the females, the degree of competition with other males, the physiological limitations of the species, predation risks and other factors (Brown 1964, Alcock et al. 1978). Exact probabilities associated with a given mating strategy may be extremely difficult to obtain, especially when matings are rarely observed and when females presumably mate only once in their lifetime. However, relative probabilities may be obtained by studying the daily and seasonal activities of males and females. A comparative approach, utilizing the ecological and ethological characteristics of closely related species may also help in understanding the factors determining the optimal mating strategy.

Males of Philanthus psyche are territorial in an area where potential mates are most likely to occur, that is, the nesting area. There are four other rendezvous places at which copulation is known to occur in the Sphecidae (Alcock et al. 1978). These are: the hunting area, flowers (nectar sites), landmark flyways and the 
nest entrance. Why is there a greater probability for males of $P$. psyche of intercepting a receptive female in the general nesting area, rather than in one of the other four above mentioned locations?

As far as the first three rendezvous places are concerned, they should be fairly localized in order for the chance of encountering a female to be sufficiently high relative to the nesting area. At Roggen, females of $P$. psyche prey upon a diverse array of small hymenopterans (at least nineteen species in eight families; Evans unpublished data). Such a great variety of prey, assuming they themselves have diverse feeding habits as a group, would not likely be found in one place. Therefore, it is likely that the female hunting area is not concentrated. There are also no obvious concentrated patches of flowers of the type that females are likely to feed upon (e.g., Eriogonum spp.). Therefore, since foraging and feeding sites are relatively diffuse, clumping of females in these sites is improbable. As an effect of the above, there would be no concentrated landmark flyways between the nesting area and the foraging and/or feeding localities over which the females would be likely to pass. Males of $P$. zebratus, in the Jackson Hole, Wyoming aggregation of this species, intercept females in flyways above the nesting area (Evans and O'Neill 1978).

Mating at the nesting entrance occurs in the sphecids Oxybelus subulatus (Peckham 1977) and Oxybelus sericeus (Bohart and Marsh 1977, Hook 1978). In these species the male is territorial at or nearby the nest entrance, mating with the female each time she returns with prey. Although he concentrates his activities on a single female, it is assured that ther eggs are fertilized by him. Males of $P$. psyche often attempt to mate with females working at the nest entrance but in all cases observed are unsuccessful, as the female wards off all efforts of the males or temporarily leaves the area. Without the prospect of multiple matings, it would not pay the male to wait at the nest entrance for the female as the time and energy could be better spent searching for other females.

Are males territorial in the nesting area because nesting females are present or because virgin females emerge there? In species in which the females mate only once, a male would gain an advantage by locating females as close to the beginning of their receptive period as possible. Assuming this, it may actually be the female emergence area that the male is interested in as a territory location. Males that scent mark closest to the emergence points would most likely be successful if females mate upon emergence for the first 
time. Males of the cicada-killer wasp, Sphecius speciosus establish territories near emergence holes and mate with newly emerged females (Lin 1963). However, there is evidence that in Philanthus spp. (including $P$. psyche) males do not establish territories until the females begin nesting; suggesting that mating does not occur at emergence but at some point during the nesting sequence. In $P$. psyche, P. bicinctus (Gwynne in preparation), P. zebratus (Evans and O'Neill 1978 and unpublished), P. triangulum (Simon-Thomas and Poorter 1972), P. multimaculatus (Alcock 1975a), and P. pulcher (personal observation) copulations were observed after females began nesting.

Given that the general nesting area seems to be the location with the highest probability of encountering a female that becomes sexually receptive sometime during the nesting sequence, a male of $P$. psyche can identify this spot by simply establishing a territory where he first emerged since the previous year's nesting area is likely to be this year's. Even if successional changes result in females moving a short distance to a new nest area, the habitat type is such that males should be able to recognize it and move with them. Therefore, following Alcock's (1975a, see introduction) criteria, a territorial sphecid such as $P$. psyche is characterized by clumping of females and an apparent ability of males to locate areas where this occurs.

The third of Alcock's criteria is the defendability of the territory in terms of the male's time and energy budget. One limitation on defendability is the amount of time spent on intraspecific male-male encounters, a function of the relative population density. If a male spends too much time on aggressive interactions with conspecific males, he wastes time and energy that could be used for scent marking and contacting females. Although these encounters are common, they by no means occupy the majority of the male's time. In addition, the territories are nonresource-based (i.e., they contain no food, plants, or foraging sites and males do not control access to nesting sites). Thus, defendability is not limited by the need to include resources in the territory; which, if a minimum number were necessary, might result in territories too large to be defended and occupied exclusively. Several consistently occupied territories of this species contained only one plant.

Evidence thus far collected substantiates the suggestion of Alcock (1975a) that abdomen dragging functions to deposit a pheromone. However, at this point in the research a description of the specific 
role that the chemical plays in the mating system of Philanthus spp. is not possible; though some educated guesses can be made. The common occurrence of interactions between non-territorial and territorial males on the latter's territory suggests that scent marking does not function to warn conspecific males that they are intruding at another's perch, as commonly occurs in mammals (Shorey 1977) and in certain species of ithomiine butterflies (Pliske 1975). In fact, something to the contrary may occur. An intruding male could capitalize on the energetic investment of another male by usurping a territory on which a pheromone has already been applied (Alcock 1975a). The advantage of the action depends upon the persistancy of the chemical. It also seems unlikely that the combined pheromone of all territorial males is equivalent to a lek, serving to attract females to the general area. Females chose the location based on requirements for nesting not because of the presence of the males. In P. triangulum (Simon-Thomas and Poorter 1972) and in P. zebratus where the territories are some distance from the nests, the function of the pheromone in attracting females is obvious. In P. psyche and P. bicinctus (Gwynne 1978) where the territories are within the nesting area the function is less obvious unless short range communication is useful. Alternatively or simultaneously the pheromone may function as an aphrodisiac stimulating the female to copulate, as has been shown in a variety of insects (Butler 1970).

\section{SUMMARY}

The general predictions made by Alcock (1975a) concerning the evolution of a territorial mating strategy in male sphecids are borne out in Philanthus psyche. That is, females are clumped in space in a manner which the males can predict and the potential territories are defendable by the males in terms of time and energy limitations. Males of $P$. psyche apply a pheromone to plants surrounding the territory. This is believed to attract sexually receptive females. Male behavior associated with pheromone usage varies with respect to various ecological factors (e.g., wind speed, wind direction). As shown by a study of the "swirling flights" of males, this species shows true aggression, and thus, true territoriality. Pursuit behavior of the males functions in investigating intruders on the territory that may be potential mates and is not an aggressive response. 


\section{ACKNOWLEDGMENTS}

I would like to thank Dr. Howard E. Evans for initiating this study and for help throughout the course of the research. This paper is dedicated to him on the occasion of his sixtieth birthday. Thomas A. Gorell, Thomas Bennett and James Ellis made important suggestions in the early stages of the study. Darryl T. Gwynne, Mary Hathaway, Allan Hook, and William Rubink reviewed the manuscript. This paper is part of a study of the comparative behavior of solitary wasps, supported by the National Science Foundation, Grant No. BNS 76-09319 to Howard E. Evans.

\section{Literature Cited}

Alcock, J.

1975a. Territorial behavior by males of Philanthus multimaculatus (Hymenoptera: Sphecidae) with a review of territoriality in male sphecids. Anim. Behav. 23(4): 889-895.

1975b. The behavior of western cicada-killer males Sphecius grandis (Sphecidae, Hymenoptera). J. Nat. His. 9: 561.

AlCOCK, J. ET AL.

1978. The ecology and evolution of male reproductive behavior in the aculeate Hymenoptera. Zoo. J. Linn. Soc. 64: 293-326.

BAKER, R. R.

1972. Territorial behavior of the nymphalid butterflies, Aglais urticae (L.) and Inachis io (L.). J. Anim. Ecol. 41: 453-469.

BARASH, D. P.

1977. Sociobiology and Behavior. Elsevier: New York.

Bohart, R. M. and E. E. Grissell

1975. California wasps of the subfamily Philanthinae (Hymenoptera: Specidae). Bull. of the California Insect Survey, Volume 19. University of California Press.

Bohart, R. M. AND P. M. MARSh

1960. Observations on the habits of Oxybelus sericeum Robertson (Hymenoptera: Sphecidae). Pan-Pac. Ent. 36: 115-118.

Bohart, R. M. And A. S. Menke

1976. Sphecid Wasps of the World. Berkeley: University of California Press.

Breed, M. D., C. M. Hinkle and W. J. Bell

1975. Agonistic behavior in the german cockroach, Blattella germanica. Z. Tierpsychol. 39: 24-32.

BROWN, J. L.

1964. The evolution of diversity in avian territorial systems. Wilson Bull. 6: 160-169.

1975. The Evolution of Behavior. New York: W. W. Norton and Co., Inc. 
Butler, C. G.

1970. Chemical communication in insects: behavior and ecologic aspects. Pp. 36-78 in Advances in Chemoreception, Vol. 1, Communication by Chemical Signals. J. W. Johnson and A. Turk eds. New York: AppletonCentury-Crofts.

EDMUNDS, J.

1976. The defensive behavior of Ghanaian praying mantids with a discussion of territoriality. Zoo. J. Linn. Soc. 58: 1-37.

EICKWORT, G.

1977. Male behavior in the mason bee Hoplitus anthocopoides (Hymenoptera: Megachilidae). Anim. Beh. 25(3): 542-554.

Evans, H. E.

1966. The Comparative Ethology and Evolution of the Sand Wasps. Harvard Univ. Press: Cambridge, Mass. xiv +526 pp.

1970. Ecological-behavioral studies of the wasps of Jackson Hole, Wyoming. Bull. Mus. Comp. Zool. 140(7): 451-511.

1975. Nesting behavior of Philanthus albopilosus with comparisons between two widely separated populations. Ann. Amer. Ent. Soc. 68(5): 888-892.

Evans, H. E. AND K. M. O'Neill

1978. Alternative mating strategies in the digger wasp Philanthus zebratus Cresson. Proc. Nat. Acad. Sci. 75(4): 1901-1903.

Fletcher, D. J. C. AND J. M. BRAND

1968. Source of the trail pheromone and method of trail laying in the ant Crematogaster peringueyi. J. Insect Physiol. 14: 783-88.

Gwynne, D. T.

1978. Male territoriality in the bumblebee wolf, Philanthus bicinctus Mickel (Hymenoptera: Sphecidae): Observations on the behavior of individual ठิ̊. Z. Tierpsychol. 47: 89-103.

GWynne, D. T. AND K. M. O'NeILL

Sex-biased predation as a result of male territoriality in Philanthus (Hymenoptera: Sphecidae). In press, J. Kans. Ent. Soc.

Hook, A. W.

1978 Sex, territoriality and biology of Oxybelus sericeus Robertson (Hymenoptera: Specidae). M.S. Thesis, University of Georgia.

Humason, G. L.

1967. Animal Tissue Techniques. 2nd ed. San Francisco: W. H. Freeman and Co.

HARRINGTON, H. D.

1964. Manual of Plants of Colorado. 2nd ed. Sage Books, Chicago.

LiN, N.

1963. Territorial behavior in the Cicada Killer Wasp, Sphecius speciosus (Drury) (Hymenoptera: Sphecidae). Behaviour XX(1-2): 115-133.

Michener, C. D.

1974. The Social Behavior of Bees. Cambridge, Mass: Harvard University Press.

MORRIS, G. K.

1971. Aggression in male conocephaline grasshoppers (Tettigoniidae). Anim. Behav. 19(1): 132-137. 
Peckham, D. J.

1977. Reduction of miltogrammine cleptoparasitism by male Oxybelus subulatus (Hymenoptera: Sphecidae). Ann. Ent. Soc. Amer. 80(6): 823.

Pliske, T. E.

1975. Courtship behavior and use of chemical communication by males of certain species of ithomiine butterflies (Nymphalidae: Lepidoptera). Ann. Ent. Soc. Amer. 68(6): 935.

SHOREY, H. H.

1977. The adaptiveness of pheromone communication. Proc. XV Int. Congress of Entomology.

Simon-Thomas, R. T. And E. P. R. Poorter

1972. Notes on the behavior of males of Philanthus triangulum (F.) (Hymenoptera: Sphecidae) Tijdschrift Voor Entomologie, Deel 115, AFL. 2,141-151.

SOWER, L. L. ET AL.

1973. Sex pheromones of Lepidoptera. XLI. Factors limiting potential distance of sex pheromone communication in Trichoplusia ni. Ann. Ent. Soc. Amer. 66(5): 1121-1122.

Steiner, A. L.

1978. Observations on spacing, aggressive and lekking behavior of digger wasp males of Eucerceris flavocincta (Hymenoptera: Sphecidae; Cercerini). J. Kans. Ent. Soc. 51(3): 492-498.

WILSON, E. O.

1971. The Insect Societies. Cambridge, Mass.: Harvard University Press. 

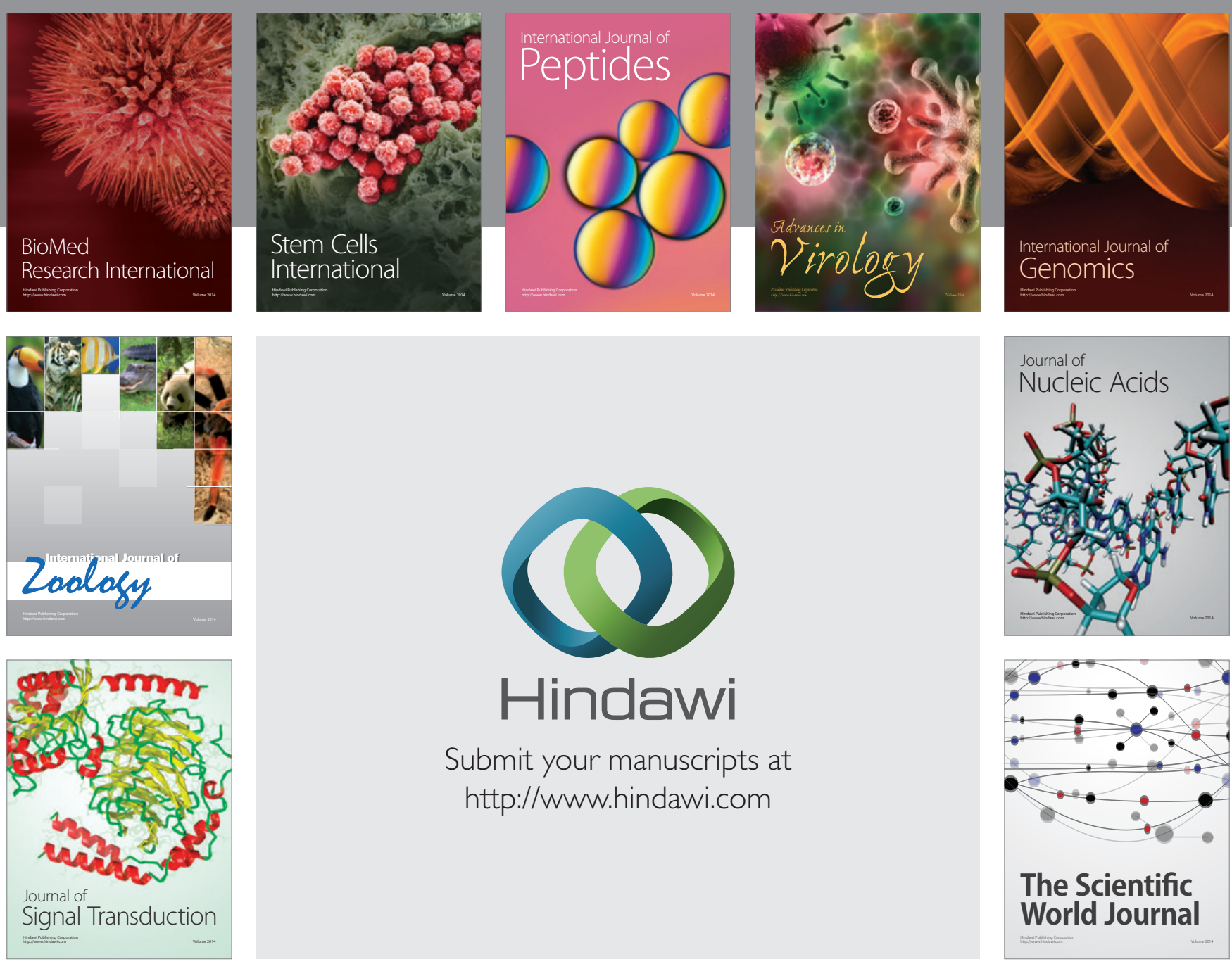

Submit your manuscripts at

http://www.hindawi.com
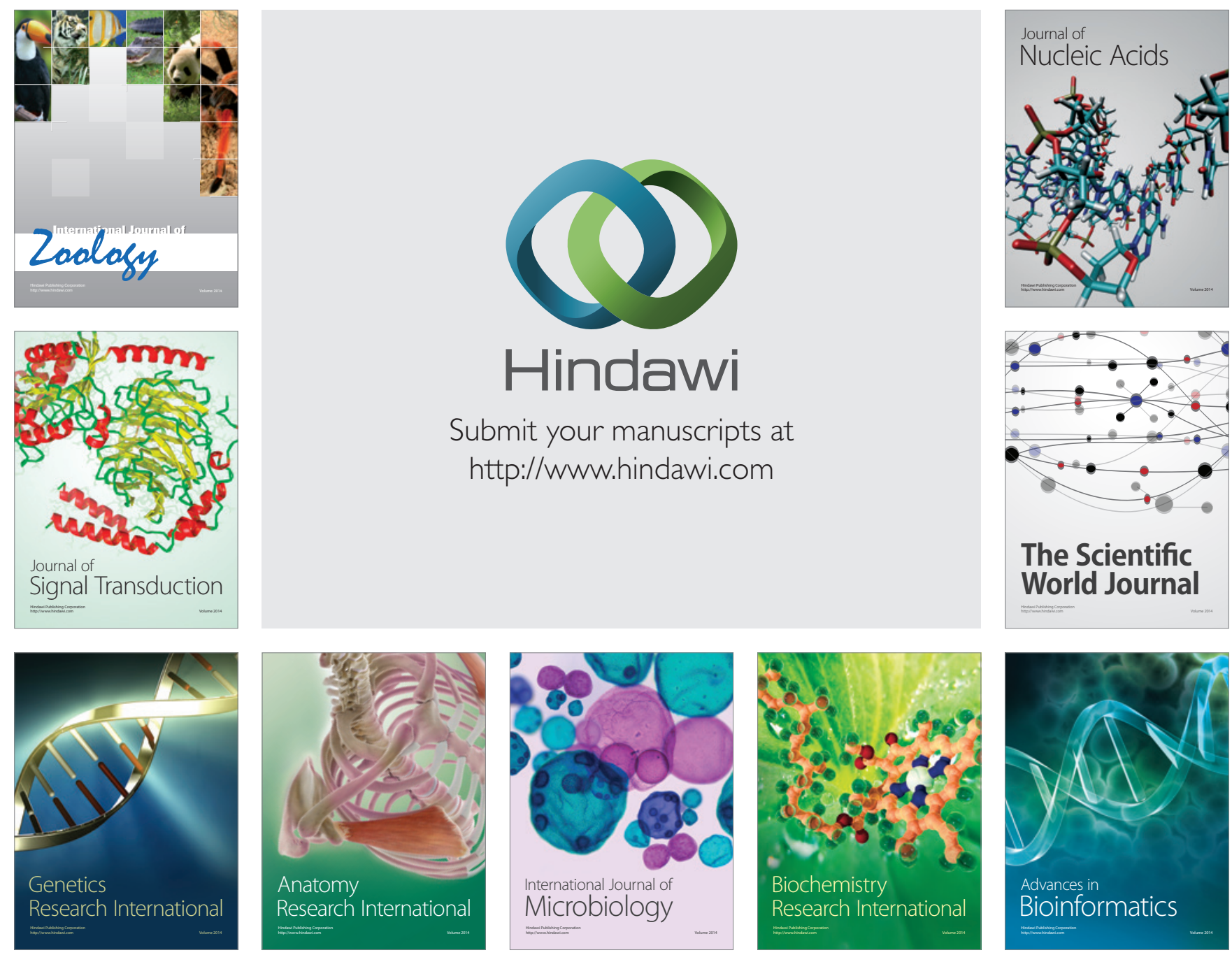

The Scientific World Journal
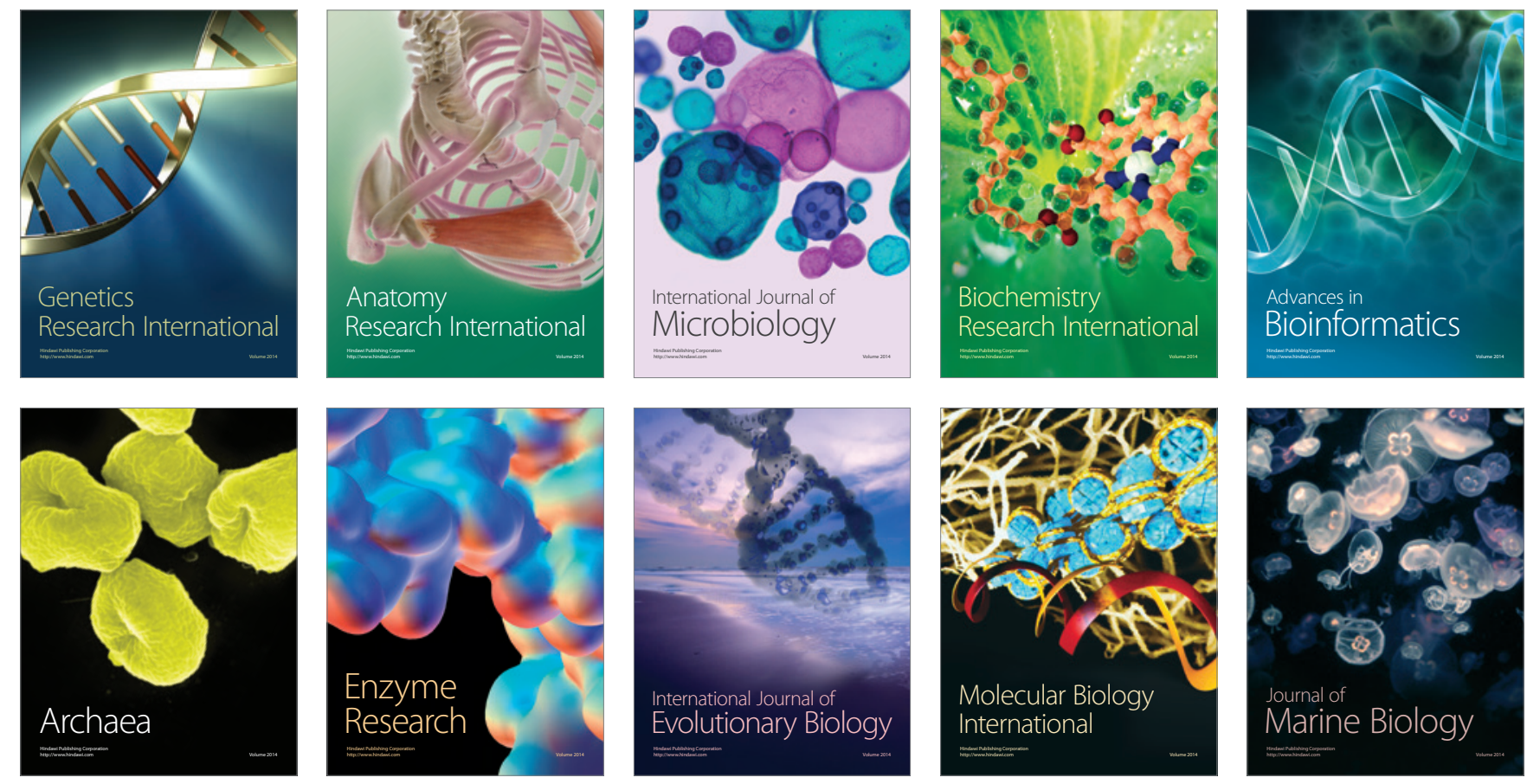